\title{
Vascular Responses to Shear Stress: The Involvement of Mechanosensors in Endothelial Cells
}

\author{
C.Y. Ngai* and X. Yao \\ Li Ka Shing Institute of Health Sciences, The Chinese University of Hong Kong, Hong Kong, China
}

\begin{abstract}
Shear stress, the frictional drag on the endothelium from blood flow, is a major determinant of vascular physiology and pathology. Due to the pulsatile nature of blood flow, blood vessels are subjected to significant variations in mechanical forces. Endothelial cells situated at the interface between blood and the vessel wall play a crucial role in detecting and responding to the mechanical forces generated by shear stress. Multiple sensing mechanisms are used by endothelial cells to detect changes in mechanical forces, leading to the activation of signaling networks. This review attempts to bring together recent findings on the mechanosensors present in the endothelial cells, and the regulation of endothelium-derived vasoactive autacoid production by shear stress.
\end{abstract}

Keywords: Shear stress, endothelial cells, mechanosensors, flow.

\section{INTRODUCTION}

Endothelial cells, which line the inner surface of all blood vessels in the entire cardiovascular system, not only serve as a selective barrier for macromolecular permeability between blood and the vessel wall but also play a crucial role in controlling vascular tone and homeostasis. For example, endothelial cells produce growth-promoting and growthinhibiting substances which affect vascular remodeling; secrete pro-coagulant, anti-coagulant, and fibrinolytic agents to modulate hemostasis and thrombosis; express chemotactic and adhesion molecules on their membrane surfaces to mediate inflammatory responses; and release vasodilators and vasoconstrictors to regulate vascular smooth muscle cells contraction. Impairment of these functions may lead to atherosclerosis and/or thrombosis [1-3].

Endothelial cells are constantly exposed to hemodynamic stimuli due to the pulsatile nature of blood flow. Hemodynamic forces are the most physiologically relevant determinants for the continuous activation of endothelial cells. Hemodynamic forces can be resolved into two principal vectors which are shear stress and pressure [4]. Shear stress is a dragging mechanical force acting at the interface between flowing blood and the vessel wall. Pressure is acting normal to the vessel wall, which imposes circumferential stretch to the tissue. Shear stress acts through the endothelial cells to acutely regulate vessel tone and chronically alter arterial structure and remodeling [5]. Thus endothelial cells form a complex mechanical signal-transduction interface between flowing blood and the vessel wall.

Mechanical stimuli are transformed into intracellular chemical signals in endothelial cells. It is particularly important in arteries, in which blood flow regulates vascular tone

*Address correspondence to this author at the School of Biomedical Sciences, Chinese University of Hong Kong, Hong Kong, China;

Tel: 852-26321174; Fax: 852-26497286; E-mail: jacq64@yahoo.com.hk and arterial remodeling. The ability of endothelial cells to sense a flow stimulus is the earliest stage in the process of shear stress-induced mechanotransduction and is a prerequisite to downstream cellular responses. Multiple molecular elements have been suggested to be involved in sensing the flow stimulus acting on endothelial cells. They include ion channels, cytoskeleton, tyrosine kinase receptors, caveolae, $\mathrm{G}$ proteins, and cell-matrix and cell-cell junction molecules such as integrins, platelet endothelial cell adhesion molecule1 (PECAM-1) and adherens junctions [6, 7]. The field is rapidly expanding with more possible candidates emerged and more elaborate mechanisms proposed. This review aims to summarize recent development on flow mechanosensors in endothelial cells.

An important consequence of hemodynamic force transduction is the acute regulation of arterial diameter. This is mediated by changes in the generation and release of endothelium-derived autacoids. The vasodilators nitric oxide (NO) and prostacyclin $\left(\mathrm{PGI}_{2}\right)$, and the vasoconstrictor endothelin-1 (ET-1) are the best characterized endotheliumderived autacoids. Increasing amount of evidence supports the role of endothelium-derived hyperpolarizing factor (EDHF) and reactive oxygen species (ROS) in flow vasodilation. In this review, we will also summarize recent development in flow-induced autocoids production with emphasis placed on EDHF and ROS.

\section{MOLECULES INVOLVED IN FLOW SHEAR FORCE SENSATION}

\subsection{Ion Channels}

Ion channel activation is one of the fastest known responses to flow in endothelial cells. The flow-sensitive ion channels have been proposed as candidate flow sensors. Various types of flow-sensitive ion channels have been identified in endothelial cells. They include a few subtypes of TRP (transient receptor potential) channels, P2X4 purinoceptors, $\mathrm{K}^{+}$channels and $\mathrm{Cl}^{-}$channels. 


\subsubsection{The Vascular Mechano-Sensitive TRP Channels}

TRP channels was first described by Consens $e t$ al. in a Drosophila mutant that had an impaired visual transduction response [8]. In addition to its response to light, TRP channels mediates responses to various stimuli such as mechanical, chemical and osmolarity.

TRP channels consist of six transmembrane segments which are linked by similar lengths of cytoplasmic or extracellular loops and a short hydrophobic stretch between segments 5 and 6 which is predicted to be the pore-forming region. Both the $\mathrm{N}$-terminal and $\mathrm{C}$-terminal are facing the cytosol and show similar topologies of voltage-gated $\mathrm{K}^{+}$, $\mathrm{Na}^{+}, \mathrm{Ca}^{2+}$ channels and cyclic nucleotide-gated channels. The TRP superfamily can be classified into seven subfamilies based on homology: TRPC (C for canonical), TRPV (V for vanilloid), TRPM (M for melastatin), TRPP (P for PKD), TRPML (ML for mucolipin), TRPA (A for ankyrin) and TRPN ( $\mathrm{N}$ for NOMPC). These subunits associate as tetramers with possible heteromultimerization [9].

TRPP1/TRPP2, TRPV4, TRPC3 and TRPM7 have been localized in endothelial cells and/or smooth muscle cells. They have been reported to be mechanosensors responding to shear stress [10-13].

\subsubsection{TRPP1/TRPP2-the Polycystin Complex}

TRPP1 and TRPP2 are also known as polycystin-1 (PC1) and polycystin-2 (PC2) which are encoded by $P K D 1$ and $P K D 2$ respectively. Mutations in either of these two genes result in a common lethal genetic disease named as autosomal dominant polycystic kidney disease (ADPKD) which is characterized by the formation of numerous fluid-filled cysts in the kidney.

TRPP1 is a large integral membrane glycoprotein ( 460 $\mathrm{kDa}$ ). It comprises of a large $\mathrm{N}$-terminal extracellular region, 11 predicted transmembrane-spanning segments and relatively short intracellular carboxyl terminal domain [14]. The large extracellular region, spanning more than 3000 amino acids, contains a number of adhesive domains that implicate TRPP1 in cell-cell and cell-matrix interactions. The Cterminal domain of TRPP1 can interact with the C-terminal domain of TRPP2 and various proteins involved in cellular signaling [15].

TRPP2 shows moderate similarity to the last six transmembrane segments of TRPP1. It has a predicted topology of a TRP channel [16]. It contains an endoplasmic reticulum (ER) retention signal within its $\mathrm{C}$-terminal domain, which prevents trafficking to the cell surface. The intracellular Cterminal region of TRPP2 also contains a $\mathrm{Ca}^{2+}$-binding EFhand domain. The extracellular loop-linking putative transmembrane segments 5 and 6 are thought to harbor the poreforming sequence. TRPP2 forms a nonselective cationic channel that conduct s both monovalent $\left(\mathrm{Na}^{+}, \mathrm{K}^{+}\right)$and divalent $\left(\mathrm{Ca}^{2+}\right)$ ions [17].

TRPP1 and TRPP2 form a shear stress-activated $\mathrm{Ca}^{2+}$ influx pathway in renal epithelial cells [18]. The TRPP1/TRPP2 complex was found to be expressed at the plasma membrane of the primary cilium in epithelial cells. The primary cilia project into the fluid-filled tubular lumen and act as the mechanical sensor for fluid flow. Mechanical stress of the primary cilia induces intracellular $\mathrm{Ca}^{2+}$ changes.
Kidney epithelial cells isolated from transgenic mice that lack functional TRPP1 fail to induce a $\mathrm{Ca}^{2+}$ influx in response to shear stress. Similarly, blocking antibodies against TRPP1 or TRPP2 inhibit the flow response in wild-type cells [18]. Nauli et al. propose that TRPP1 and TRPP2 physically interact with each other to form a mechanosensor that detects fluid flow in renal epithelial cells. Within the complex, TRPP1 serves as a sensor to transduce the flow stimulus to TRPP2, which allows $\mathrm{Ca}^{2+}$ influx.

A recent study of Nauli's group provides evidence that TRPP1 and polaris, which is encoded by $T g 737$ and required for cilia structure, mediate a mechanism by which endothelial cells sense and respond to fluid shear stress [10]. Aortic endothelial cells isolated from $P k d l$ and $T g 737$ knockout mice are unable to transmit extracellular shear stress into intracellular calcium signaling and biochemical nitric oxide (NO) synthesis. Furthermore, TRPP1 localized in the basal body of $T g 737$-deficient endothelial cells is insufficient for a fluid shear stress response. Proper localization and function of TRPP1 in cilia are required for the mechanotransduction in aortic endothelial cells.

A new role for polycystin-2 in transmitting extracellular shear stress to intracellular NO biosynthesis was proposed recently [19]. It has been demonstrated that the normal expression level and localization of polycystin- 2 in cilia is required for the endothelial cilia to sense fluid shear stress through a complex biochemical cascade, involving calcium, calmodulin, Akt/PKB, and protein kinase C. Mouse endothelial cells with knockdown or knockout of $P k d 2$ lose the ability to generate NO in response to fluid shear stress. Consistent with mouse data, endothelial cells generated from ADPKD patients do not show polycystin-2 in the cilia and are unable to sense fluid flow. Furthermore, the ciliary polycystin- 2 in the isolated artery responds specifically to shear stress but not to mechanical stretch, a pressurized biomechanical force that involves purinergic receptor activation.

\subsubsection{TRPV4}

TRPV4 (also called OTRPC4, TRP12, and VR-OAC) might be of special interest within the endothelial TRP channels due to its moderately high $\mathrm{Ca}^{2+}$ permeability [20]. In addition, it has been shown to be opened by diverse physical and chemical stimuli such as cell swelling [21] and shear stress [11, 22], moderate warmth $\left(>27^{\circ} \mathrm{C}\right)$ [23], low pH [24], $4 \alpha$-phorbol 12,13-didecanoate (4aPDD), arachidonic acid (AA) and its metabolite 5,6 epoxyeicosatrienoic acid [25].

A shear stress-induced TRPV4-mediated $\mathrm{Ca}^{2+}$ entry has been demonstrated in heterologous expression systems [22]. HEK293 cells were transfected with TRPV4 so as to evaluate the effect of shear stress on channel activation. At room temperature, fluid shear stress had little or no effect on intracellular concentration of $\mathrm{Ca}^{2+}\left(\left[\mathrm{Ca}^{2+}\right]_{\mathrm{i}}\right)$ in transfected HEK 293 cells. In contrast, when studies were done at $37^{\circ} \mathrm{C}$, fluid shear stress induced $\left[\mathrm{Ca}^{2+}\right]_{i}$ oscillations with a marked increase in peak magnitude of $\left[\mathrm{Ca}^{2+}\right]_{i}$. Moreover, $\left[\mathrm{Ca}^{2+}\right]_{\mathrm{i}}$ increased proportionally with step elevations in shear stress. It revealed a temperature-induced potentiation or switching on of a channel signaling pathway. It has also been demonstrated that TRPV4 is activated by shear stress in native collecting duct cells [26]. 
The role of TRPV4 in shear stress-induced vasodilation was also investigated in rat conduit arteries and small-sized Austroboletus gracilis [11]. Shear stress induced vasodilation in conduit arteries and $A$ gracilis, and this response was greatly blocked by the TRPV4 inhibitor ruthenium red. However, TRPV4 might not serve as the mechanosensor in this response. It was suggested that $\mathrm{PLA}_{2}$-mediated AA release after shear stress stimulation activated TRPV4. $\mathrm{Ca}^{2+}$ entry through endothelial TRPV4 triggered NO-dependent vasodilation in rat conduit arteries, and NO-dependent and EDHF-dependent vasodilaton in small-sized A gracilis. Furthermore, shear stress induced vasodilation is significantly reduced in carotid arteries from TRPV4 knockout (-/-) mice [27].

\subsubsection{TRPC3}

TRPC3, a member of the transient receptor potential family of ion channels, has been shown to be activated by agonist activation of plasma membrane G-protein-coupled receptors, by synthetic diacylglycerols, and by depletion of intracellular $\mathrm{Ca}^{2+}$ stores in some cell types [28-30].

The functional role of TRPC3 in flow (shear stress)induced vasodilation of isolated rat small mesenteric arteries was explored using a specially designed antisense oligo against TRPC3 [12]. 72 hours-treatment of the antisenseoligo via tail vein injection markedly decreased the TRPC3 expression in mesenteric arteries. The antisense oligo treatment reduced the magnitude of flow-induced vasodilation by $\sim 13 \%$ and attenuated the magnitude of endothelial $\left[\mathrm{Ca}^{2+}\right]_{\mathrm{i}}$ rise in response to flow. It can be concluded that TRPC3 is involved in flow-induced vasodilation in rat small mesenteric arteries probably by mediating $\mathrm{Ca}^{2+}$ influx into endothelial cells.

\subsubsection{TRPM7}

TRPM7 or TRP-PLIK (transient receptor potentialphospholipase interacting kinase) is widely expressed in tissues including vascular smooth muscle and endothelium [31]. It is a $105 \mathrm{pS}$ outward rectifier and is permeable to $\mathrm{Na}^{+}$ and $\mathrm{Ca}^{2+}$. TRPM7 expression yields a non-selective wholecell current whose activity is controlled by its own carboxyterminal kinase [32]. The TRPM7 current is dependent on cytoplasmic $\mathrm{Mg}^{2+}$ and hydrolysable ATP levels.

The whole-cell currents of the TRPM7 channel heterologously expressed in human embryonic kidney (HEK) 293 cells were found to be augmented by shear stress. The shear stress-induced augmentation was independent of exocytosismediated incorporation of the channel protein into the plasma membrane [33]. Alternately, it was shown that TRPM7 is translocated within cells in response to laminar flow [13]. The number of TRPM7 molecules localized at or near the plasma membrane was increased up to two-fold in less than 100 s after increasing the shear stress. This increase correlated to the increases in TRPM7 current amplitude. In vascular smooth muscle cells, fluid flow increased endogenous native TRPM7 current amplitude suggesting that this channel may be involved in pathological response to vessel wall injury.

\subsubsection{P2X4 Purinoceptors}

$\mathrm{P} 2 \mathrm{X}$ receptors are membrane ion channels that open in response to the binding of extracellular ATP [34]. When
ATP binds to P2X receptors on the surface of cells, extracellular $\mathrm{Ca}^{2+}$ enters and activates signal transduction pathways that evoke a variety of cellular responses. P2X receptors are distributed throughout the entire body and are involved in the regulation of the physiological function of many tissues and organs. Seven P2X subtypes, P2X1-7, have been cloned. They contain two transmembrane domains and function as cation channels in the form of hetero- or homo-oligomers [35].

$\mathrm{P} 2 \mathrm{X} 4$ is the most abundantly expressed $\mathrm{P} 2 \mathrm{X}$ receptor subtype in vascular endothelial cells [36, 37]. It is predominantly expressed in ECs cultured from human umbilical vein, pulmonary artery, aorta, and skin microvessels [38].

It has been shown that $\mathrm{P} 2 \mathrm{X} 4$ is the major contributor to flow-induced $\mathrm{Ca}^{2+}$ influx in endothelial cells [39]. Shear stress-dependent $\mathrm{Ca}^{2+}$ influx occurs in human umbilical vein endothelial cells (HUVECs) when exposed to flow in the presence of extracellular ATP. The treatment of HUVECs with antisense oligonucleotides designed to knock down the expression of $\mathrm{P} 2 \mathrm{X} 4$ abolishes the $\mathrm{Ca}^{2+}$ response to flow. HEK 293 cells, which show no $\mathrm{Ca}^{2+}$ response to flow, express P2X4 receptors and exhibit shear stress-dependent $\mathrm{Ca}^{2+}$ influx when transfected with $P 2 R X 4$ cDNA. To further evaluate the significance of $\mathrm{P} 2 \mathrm{X} 4$ receptors in shear stressinduced response, $P 2 r x 4$-deficient mice were generated using embryonic stem cells [40]. $P 2 r x 4^{-/}$mice do not have normal endothelial cell responses to flow which include $\mathrm{Ca}^{2+}$ influx and subsequent production of the potent vasodilator NO. In addition, the vasodilatory response of cremaster muscle arterioles and mesenteric arteries to increased blood flow was much weaker in $P 2 r \times 4^{-/}$mice compared with wild-type mice. Thus, P2X4 is crucial to flow-dependent control of vascular tone.

\subsection{3. $\mathrm{K}^{+}$Channels}

Earlier studies have shown that shear stress activates the inward-rectifying $\mathrm{K}^{+}$current leading to cell membrane hyperpolarization [41, 42]. Whole-cell patch-clamp recordings of single arterial endothelial cells exposed to controlled levels of laminar shear stress in capillary flow tubes demonstrated the evidence for a $\mathrm{K}^{+}$selective, shear stress-activated ionic current [41]. Treatment of endothelial cells with blocking agents to $\mathrm{K}^{+}$channel such as barium chloride or tetraethylammonium inhibited the induction of NO by shear stress and the induced expression of endothelial cell NO synthase (eNOS) and transforming growth factor beta-1 [43, 44]. The findings support that $\mathrm{K}^{+}$channel is important in mediating shear stress responsiveness.

More recently, a $\mathrm{K}_{\mathrm{ir}} 2.1 \mathrm{~K}^{+}$ion channel that responds to shear stress was cloned from bovine aortic endothelial cells [45]. An increase in $\mathrm{K}^{+}$current was observed in oocytes and HEK cells expressing the exogenous endothelial $\mathrm{K}_{\mathrm{ir}} 2.1$ channel. Protein tyrosine kinase is required for the $\mathrm{K}_{\mathrm{ir}} 2.1$ channel shear stress sensitivity.

Another study focused on the role of $\mathrm{Ca}^{2+}$-activated potassium channels $\left(\mathrm{K}_{\mathrm{Ca}}\right)$ in flow-induced arteriolar dilation in skeletal muscle and mesentery of rats [46]. Intraluminal administration of iberiotoxin, an inhibitor of high conductance $\mathrm{K}_{\mathrm{Ca}}$ channels $\left(\mathrm{BK}_{\mathrm{Ca}}\right)$, eliminated the flow-induced dilations of the arterioles. Thus, activation of endothelial $\mathrm{BK}_{\mathrm{Ca}}$ channels in arterioles of several tissues is an obligatory step in the 
transduction of the signal initiated by changes in intraluminal shear stress, leading to the release of endothelial factors evoking dilation.

\subsubsection{Cl Channels}

Sudden exposure of endothelial cells to shear stress immediately activates inward-rectifying $\mathrm{K}^{+}$channels, leading to cell membrane hyperpolarization [41]. Simultaneously, flow stimulates outward-rectifying $\mathrm{Cl}^{-}$channels whose activation leads to membrane depolarization following the initial $\mathrm{K}^{+}$ channel-mediated hyperpolarization $[47,48]$. Hyperpolarization precedes depolarization despite the fact that the electrochemical driving force for $\mathrm{Cl}^{-}$is larger than that for $\mathrm{K}^{+}$. It suggests that flow-sensitive $\mathrm{Cl}^{-}$channels attain maximal activation more slowly than flow-sensitive $\mathrm{K}^{+}$channels. It is particularly relevant for situations where a time-varying shear stress may activate one or both channels depending on the time constant characterizing the changes in shear stress [49].

Different types of endothelial cells may express different types of flow-sensitive $\mathrm{Cl}^{-}$channels. The time dependence and outward-rectifying behavior of flow-sensitive $\mathrm{Cl}^{-}$channels resembles that of $\mathrm{Ca}^{2+}$-activated $\mathrm{Cl}^{-}$channels [50]. Another type of channels called volume-regulated anion channels (VRAC) have also been reported to exhibit sensitivity to flow, although the response is only triggered in the presence of an osmotic stress [51].

\subsection{Cell-Matrix and Cell-Cell Junction Molecules}

\subsubsection{Integrins}

The extracellular matrix is an important contributor to the mechanotransduction. It contains glycoproteins which are displaced by stretch or shear stress and interact with integrins. Integrins are a family of more than 20 transmembrane heterodimers composed of $\alpha$ and $\beta$ subunits. They participate not only to cell attachment to the substrate but also to intracellular transmission of mechanical signals.

The effects of shear stress on endothelial cell integrins include their clustering [52], association with the adaptor protein Shc [53], and binding with WOW-1, which is an antibody that specifically recognizes the activated intergrin $\alpha_{v} \beta_{3}$ [54]. The shear-induced activation involves dynamic and specific interactions between integrins and their cognate extracellular matrix ligands [55]. Indeed, in isolated coronary arteries, flow-induced vasodilation can be abrogated by addition of anti- $\beta 3$ antibodies or inhibitory RGD peptides [56]. In most cases, the cytoplasmic domain of integrins is functionally linked to various intracellular proteins that constitute the cytoskeleton and numerous kinases including focal adhesion kinase (FAK), a key regulator of biochemical cascades initiated by mechanical forces. Hence, integrins form a signaling interface between the extracellular matrix and the cell.

\subsubsection{PECAM-1}

Platelet endothelial cell adhesion molecule-1 (PECAM-1) is concentrated at cell-cell contacts and undergoes homophilic binding between adjacent endothelial cells. It plays a role in the regulation of leucocyte transmigration, cell adhesion and angiogenesis [57]. A rapid tyrosine phosphorylation of PECAM-1 was observed following the application of fluid shear stress to endothelial cells grown under static conditions
$[58,59]$. This response cannot be mimicked by $\mathrm{Ca}^{2+}$ elevating agonists or growth factor, suggesting that PECAM1 may serve as a mechanoreceptor, or part of such complex, on the endothelial cell surface $[58,60]$.

The translocation of a tyrosine phosphatase SHP-2 to endothelial cell junctions, which is dependent on PECAM-1 expression, has been observed within 5 minutes after shear stress stimulation [60]. Furthermore, the shear stress can induce phosphorylation of extracellular signal-regulated kinases (ERK) and such phosphorylation is dependent on PECAM-1 tyrosine phosphorylation, SHP-2 binding to phospho-PECAM-1, and SHP-2 phosphatase activity [60]. These results suggest that PECAM-1 participates in the mechano-sensing of shear stress in endothelial cells.

\subsubsection{Adherens Junctions}

VE-cadherin is the major adhesive protein of the adherens junction and is specific for vascular endothelial cells. It interacts with the cytoskeleton via several anchoring molecules, such as $\beta$-catenin, to transfer intracellular information [61]. Its expression is required for vascular integrity. Deletion or cytosolic truncation of VE-cadherin impairs remodeling and maturation of the vascular network, and on the cellular level it abolishes transmission of intracellular signal via vascular endothelial growth factor receptor 2 (VEGFR2) [62].

The adherens junction has been shown to play a role in the adaptation of vascular endothelial cells to long intervals of shear stress [63, 64]. In porcine aortic endothelial cells, shear stress causes partial disassembly of adherens junctions that involves complete, but temporary, loss of junctional plakoglobin and partial, transient dispersal of other catenins and VE-cadherin [63]. Adherens junctions, which form a beltlike structure contiguous with the dense peripheral band in static cultures, are reassembled into adherens plaques that localize at the ends of stress fibers that insert into cell-cell junctions. Thus, adherens junctions in endothelium exposed to physiological levels of shear stress are structurally distinct from such junctions in static endothelial cell cultures. Schnittler et al. showed that interendothelial adhesion under hydrodynamic but not resting conditions requires the junctional location of cadherins associated with plakoglobin. $\beta$-Catenin cannot functionally compensate for the junctional loss of plakoglobin, and PECAM-1-mediated adhesion is not sufficient for monolayer integrity under flow [63]. Furthermore, the role of adherens junctions in mechanosensing was demonstrated by the formation of the VEGFR2-VE-cadherin- $\beta$ catenin complex in vascular endothelial cells that stimulated by short intervals of shear stress [65]. The complex was bound to the cytoskeleton and played a role in transducing shear stress-dependent signals into the endothelium.

\subsection{Tyrosine Kinase Receptors}

VEGFR2 does not only act as a mechanosensor in the context of the adherens junction. It is rapidly phosphorylated after the onset of flow, and it forms membranal clusters and binds to the adaptor protein Shc [53]. These changes become detectable within 1 min after the application of shear stress, reach a peak in 10-15 min, and disappear in $30 \mathrm{~min}$ with continued shearing. The shear-induced activation is independent of its legand VEGF, as these responses are not af- 
fected by an anti-VEGF blocking antibody. A rapid nuclear translocation of VEGFR2 in response to flow has been reported [65]. It was also demonstrated that shear activation of VEGFR2 causes the recruitment of phosphoinositide 3kinase (PI3K) and the consequent activation of Akt and eNOS [66]. In addition, the blockade of integrins attenuates shear-induced VEGFR2 activation [52], suggesting that integrins may be upstream to VEGFR2 in the molecular network of mechano-sensing in the endothelial cells.

\subsection{Caveolae}

Caveolae are described as distinct flask-shaped invaginated structures of approximately $50-100 \mathrm{~nm}$ present at the surface of many cell types including endothelial cells, smooth muscle cells, macrophages, cardiac myocytes and fibroblasts. Different from noncaveolar regions of the surface membrane, which are mainly composed of phospholipids, caveolae have enriched cholesterol and sphingolipids. Some intracellular signaling molecules such as G proteincoupled receptors, receptor- and nonreceptor-tyrosine kinases, a number of GTPases (such as Ras and Raf), eNOS, and some components of the MAPK pathway are also enriched in caveolae [67-69].

Evidence for the involvement of caveolae in flowinduced endothelial activation mainly came from studies performed on cultured cells exposed to laminar flow in vitro. In bovine and human endothelial cells, chronic shear induces an increase in caveolae density at the luminal plasma membrane coupled with a translocation of caveolin-1 from the Golgi to the plasma membrane. Cells exposed to long-term shear flow display an increase in tyrosine phosphorylation of luminal surface proteins and activation of some well-known shear-sensitive signaling molecules (such as ERK, AKT, and eNOS) [70-73]. $\beta$-cyclodextrin, which disrupts caveolae structure by depleting cholesterol content in endothelial cells, inhibited flow activation of ERK [74]. Similarly, in rabbit aorta perfused ex vivo, cyclosporin A, which depleted cholesterol content from caveolae without disrupting their structure, decreased flow-induced eNOS phosphorylation at serine 1179 [75].

There is also in vivo evidence supporting the role of caveolin-1 function in flow-induced arterial responses in vivo [76]. In Cav-1 KO mice, chronic flow-dependent arterial remodeling and acute flow-dependent vascular dilation are both impaired. Furthermore, reconstitution of endothelial caveolin-1 into the knockout background rescued endothelial caveolae and the abnormal responsiveness of the vessels. These data suggest an important role of caveolin-1 in flowinduced vascular responses.

\subsection{G-Protein-Coupled Receptors (GPCRs) and G Pro- teins}

$\mathrm{G}$ proteins may act as primary mechanotransducers as shown by Gudi et al. G protein activation occur as quickly as $1 \mathrm{~s}$ after the onset of shear stress, and the shear stress activation of $\mathrm{G}$ proteins in endothelial cell membrane vesicles is independent of the cytoskeletal and cytosolic components [77]. Treatment of endothelial cells with anti-sense $G_{\alpha q}$ oligonucleotides inhibits shear stress-induced Ras-GTPase activity, while the transfection of $\mathrm{G}_{1 \gamma^{2}}$ enhances the shear stress-induced Ras activation [78]. It has also been reported that the shear stress-mediated activation of ERK1/2 is abolished by the treatment of endothelial cells with the $G_{i}$ inhibitor pertussis toxin [79]. In addition, shear stress increases the activity of $\mathrm{G}$ proteins reconstituted in liposomes in the absence of protein receptors [80]. The increase in the activity is attenuated if the lipid bi-layer is made more rigid by the addition of cholesterol. These findings suggest an important role of $\mathrm{G}$ proteins in flow sensing.

\subsection{The Glycocalyx}

The glycocalyx is a highly charged, glycoprotein-rich extension of the cell surface, which is connected to the cytoskeleton at the base and extend through the luminal cell surface. It can project up to $0.5 \mu \mathrm{m}$ from the endothelial plasma membrane $[81,82]$. The stability of the integral structure of the glycocalyx is significant in mechanotransduction. Selective cleavage of glycocalyx components, particularly the glycosaminoglycan heparin sulfate, abolishes both flow-mediated endothelial NO production [83] and monolayer realignment in the flow direction [84]. It was also reported that removal of hyaluronic acid glycosaminoglycans can inhibit $80 \%$ of NO production in response to shear stress [85]. In addition, the removal of chondroitin sulfate glycosaminoglycans in the glycocalyx greatly affects the contraction response to increase in shear stress in smooth muscle cells [86].

Variation in the glycocalyx spatial distribution and composition is a determinant of mechanotransduction. Redistribution of the glycocalyx from a uniform surface profile to a distinct peripheral pattern, with most molecules detected above cell-cell junction, appears to serve as a cell-adaptive mechanism by reducing the shear gradients that the cell surface experiences [84]. The importance of the glycocalyx is also evidenced in diabetic patients, who have reduced flowmediated dilation in association with a lower glycocalyx volume and an enhanced level of circulating glycocalyx elements [87].

\subsection{The Endothelial Cytoskeleton}

The number of endothelial molecules and structures that are found to be involved in shear stress transduction and signaling is growing. Some of them are localized to endothelial compartments and are not directly exposed to flow. It raises the question whether there is a common structure that can connect all these shear stress receptors together [88]. Such structure requires the ability to sense a mechanical force and transmit it to different compartments. The endothelial cytoskeleton is an attractive candidate, due to its rapid structural changes in response to flow, and its ability of binding directly or indirectly to many shear stress receptors [89-91].

Endothelial cells contain a complex network of microtubules, intermediate filaments and actin fibers that traverse the cell. These are tacked down to the basement membrane at cell-cell contacts and end in caveolae and characteristic adhesion complexes. Such construction within the cell means that there is tension across the entire endothelial cytoskeleton. Shear stress at the cell surface elicits a redistribution of these forces, which is translated into a chemical signal at the end of a filament/fiber [92].

The actin cytoskeleton was demonstrated to transduce force signaling to several endothelial compartments, includ- 
ing the cell-matrix junction and the nucleus [93-96]. Disruption of the actin cytoskeleton was shown to inhibit shear stress-mediated signaling and changes in gene expression $[97,98]$. The intermediate filament vimentin might have a central role in shear stress transduction because it is rapidly displaced in response to shear stress [99], and flow-induced dilation is markedly attenuated in mice that lack the gene that encodes vimentin [100]. Vimentin has also been shown to regulate focal contact size when stimulated by shear stress and help stabilizing cell-matrix adhesions in endothelial cells [101]. Nevertheless, the location of vimentin in this pathway remains to be determined.

\section{ENDOTHELIUM-DERIVED VASOACTIVE AUTA- COID IN RESPONSE TO FLOW SHEAR STRESS}

\subsection{Endothelium-Derived Hyperpolarizing Factor}

The term EDHF describes a variety of mechanisms that regulate endothelial cell membrane potential rather than a single factor. Initially, it was supposed the endothelium generates EDHF which diffuses out of the cells to stimulate $\mathrm{K}_{\mathrm{Ca}}$ channels on the underlying smooth muscle cells, thus eliciting hyperpolarization and inducing relaxation in an NO- and $\mathrm{PGI}_{2}$-independent manner. However, increasing evidence suggests that the initial event in all of the EDHF-mediated responses characterized to date is the hyperpolarization of endothelial cells mediated by the opening of small and intermediate conductance $\mathrm{K}_{\mathrm{Ca}}$ channels $\left(\mathrm{SK}_{\mathrm{Ca}}\right.$ and $\left.\mathrm{IK}_{\mathrm{Ca}}\right)$ [102].

The contribution of EDHF-mediated responses as a mechanism for endothelium-dependent relaxation increases as the vessel size decreases [103]. Evidence has emerged that likely EDHF candidates vary with vessel size, species and tissue beds.

Several findings support the role of EDHF in flowinduced vasodilation. Intraluminal administration of charybdotoxin or iberiotoxin (the specific inhibitors of $\mathrm{BK}_{\mathrm{Ca}}$ ) abolished flow-mediated dilation in rabbit iliac artery [104]. In a bioassay experiment using rabbit abdominal aorta with endothelium as donor vessels, it was shown that relaxation of recipient endothelium-denuded aorta to pulsatile flow was abolished by charybdotoxin [105]. In addition, blockers of endothelial $\mathrm{K}_{\mathrm{Ca}}$ channels reduce flow-induced, EDHFdependent vasodilation in the arterioles of rat skeletal muscle and mesentery [46].

A recent study shows that flow-induced, NO- and $\mathrm{PGI}_{2-}$ independent vasodilation of the murine carotid artery is sensitive to a CYP epoxygenase inhibitor as well as to a TRPV4 channel blocker [106]. Moreover, EDHF-responses and sensitivity to ruthenium red could be restored by the overexpression of a CYP epoxygenase (CYP2C9) in arteries maintained in organ culture. These observations together with the finding that shear stress induced the translocation of TRPV4 to the endothelial cell membrane suggest that the activation of the channel by CYP-derived EETs underlies the EDHF component of flow-induced vasodilation.

It has been reported that $\mathrm{H}_{2} \mathrm{O}_{2}$-like EDHF mediates flowinduced vasodilation. Shear stress induces endothelial release of $\mathrm{H}_{2} \mathrm{O}_{2}$ which acts as an EDHF that contributes to flow-induced vasodilation in human coronary arterioles from patients with heart disease [107]. The role of $\mathrm{H}_{2} \mathrm{O}_{2}$ in the flow-induced vasodilation in rat small mesenteric arteries has also been demonstrated [108]. Catalase abolishes the flow-induced dilation, while the application of exogenous $\mathrm{H}_{2} \mathrm{O}_{2}$ induces relaxation in phenylephrine-preconstricted arteries. $\mathrm{H}_{2} \mathrm{O}_{2}$ hyperpolarizes the smooth muscle cells, indicating that $\mathrm{H}_{2} \mathrm{O}_{2}$ can act as an EDHF. Indeed, the source of $\mathrm{H}_{2} \mathrm{O}_{2}$ was investigated and the results demonstrated that, during flow-induced vasodilation, $\mathrm{H}_{2} \mathrm{O}_{2}$ is generated from CYP epoxygenases and xanthine oxidase [109].

\subsection{Reactive Oxygen Species}

ROS, such as superoxide $\left(\mathrm{O}_{2}^{-{ }^{-}}\right)$and $\mathrm{H}_{2} \mathrm{O}_{2}$, are traditionally thought to be toxic by-products of cellular metabolism, which nonspecifically damage nucleic acids, proteins, lipids, and other cellular components. However, the role of ROS as signaling molecules and the importance of ROS in the regulation of various vascular cell functions have been recognized over the past few years [107, 110-113]. In vascular endothelial cells, ROS regulate vascular tone, oxygen sensing, cell growth and proliferation, apoptosis, and inflammatory responses. In addition to these regulatory functions under physiological conditions, excessive or sustained ROS have been implicated in the pathogenesis of various cardiovascular diseases, such as atherosclerosis, hypertension, diabetic cardiovascular complications, and ischemia-reperfusion injury [114].

The role of ROS in flow-induced vasodilation in various vessels of different animals as been investigated. Yan et al. [115] recently reported that flow-induced dilations are decreased in mesenteric arterioles of $\mathrm{Mn}-\mathrm{SOD}^{-} /$mice relative to wild-type control mice. The authors proposed that the associated decrease in activity of Mn-SOD leads to less dismutation of mitochondrial $\mathrm{O}_{2}{ }^{--}$and greater cytosolic trafficking of $\mathrm{O}_{2}{ }^{--}$via the voltage-dependent mitochondrial anion channel, resulting in the quenching and inactivation of NO [116]. This cycle of events leads to reduced NO-dependent relaxations. Lower levels of Mn-SOD could also result in a reduced ability to convert $\mathrm{O}_{2}{ }^{--}$in mitochondria to $\mathrm{H}_{2} \mathrm{O}_{2}$, an endogenous vasodilator. On the other hand, the vasodilator involved in flow-induced vasodilation in visceral adipose arterioles from patients with or without coronary artery disease (CAD) has been investigated [117]. Flow-induced vasodilation is mediated by NO in visceral adipose arterioles in patients without CAD. ROS contribute minimally to flowinduced vasodilation in these vessels. In visceral adipose arterioles in patients with CAD, the mechanism of flowinduced vasodilation prominently involves $\mathrm{H}_{2} \mathrm{O}_{2}$. Flowinduced ROS generation is elevated in visceral adipose arterioles in patients with CAD versus non-CAD patients. Taken together, these results suggest that, in the presence of CAD, alternative dilator mechanisms involving vascular generation of $\mathrm{H}_{2} \mathrm{O}_{2}$ replace NO-mediated mechanisms of vascular relaxation in the adipose circulation.

A variety of cellular enzyme systems are potential sources of ROS, including NADPH (nicotinamide adenine dinucleotide phosphate, reduced) oxidase, xanthine oxidase, uncoupled eNOS, AA metabolizing enzymes including CYP epoxygenase, lipoxygenase and cyclooxygenase, and the mitochondrial respiratory chain $[114,118]$. The involvement of NADPH oxidase and the enzymes of mitochondrial respiratory chain in ROS generation in response to shear stress has been demonstrated. Both shear stress and cyclic stretch 


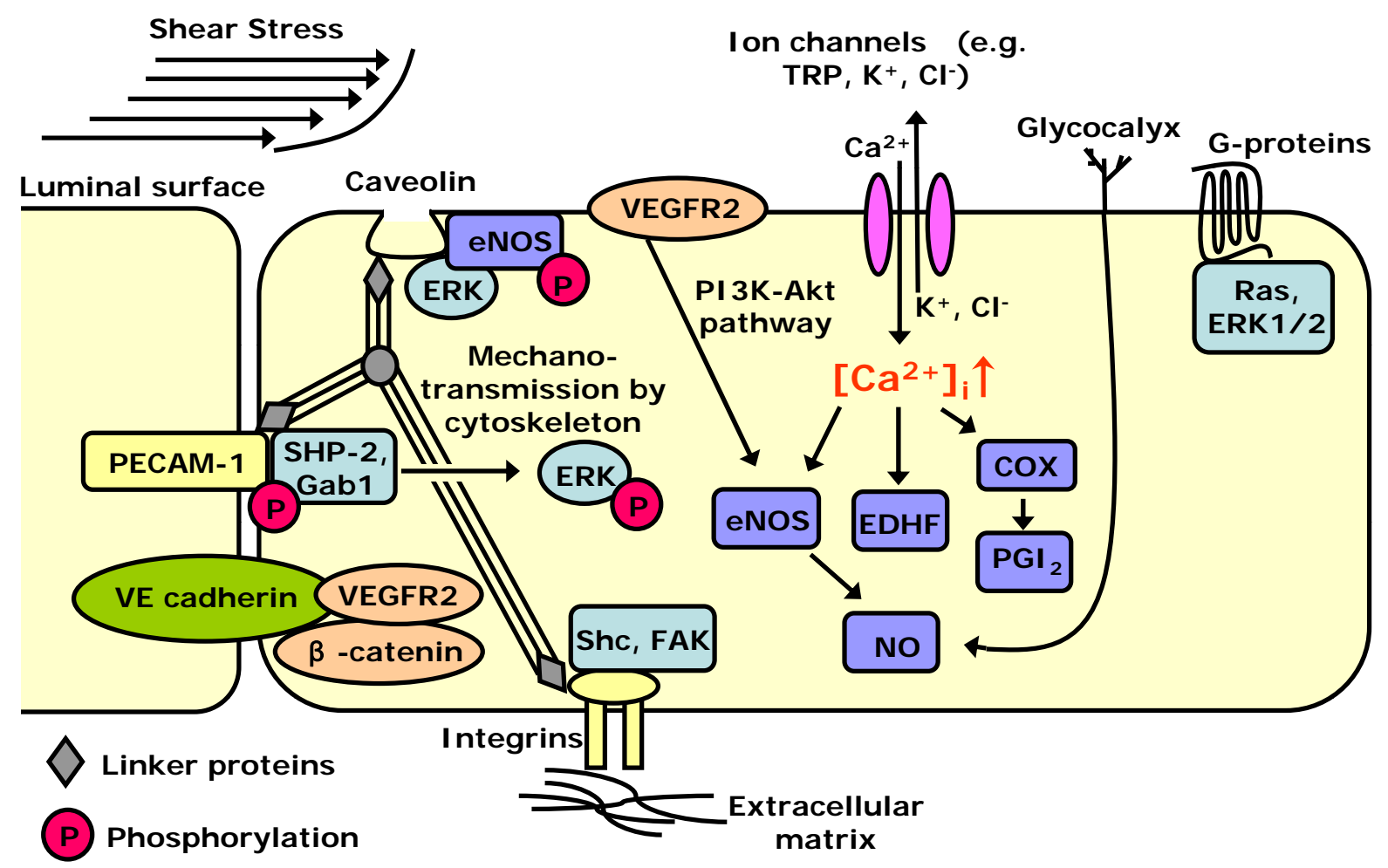

Fig. (1). The components in shear stress-induced initial response of endothelial cells.

In endothelial cells, fluid shear stress is sensed by different mechanosensors including ion channels (TRP, $\mathrm{P} 2 \mathrm{X} 4, \mathrm{~K}^{+}, \mathrm{Cl}^{-}$channels), integrins, platelet endothelial cell adhesion molecule-1 (PECAM-1), VE-cadherin, caveolae, G proteins, glycocalyx, and the endothelial cytoskeleton. Activity of ion channels results in $\mathrm{Ca}^{2+}$ influx, which leads to the production of vasodilators including NO, prostacyclin and EDHF. Shear stress is transmitted through the cytoskeleton to the basal or junctional endothelial surface, where certain integrins or PECAM-1 and VEcadherin are activated, respectively. Activated integrins associate with adaptor protein Shc and numerous kinases including focal adhesion kinase (FAK). Shear stress also induces PECAM-1 tyrosine phosphorylation and recruitment of SHP-2 and Gab1 to the cell junction. This activates a signaling cascade leading to ERK phosphorylation. At the luminal surface, shear activation of VEGFR 2 causes the recruitment of phosphatidylinositol 3 kinase (PI3K) and the consequent activation of Akt and eNOS. At caveolae, shear stress induces the activation of ERK and the eNOS phosphorylation at serine 1179. G protein activation occurs rapidly after the onset of shear stress and leads to the activation of Ras, and ERK1/2. Direct shear stress induced-signaling can occur through deformation of the luminal surface via the glycocalyx which mediates NO production.

enhance endothelial $\mathrm{O}_{2}{ }^{-}$generation [119], and pulsatile flow increases the expression of $\mathrm{p} 22^{\text {phox }}$, a subunit of NADPH oxidase [120]. In coronary arterioles from patients with coronary artery disease (CAD), $\mathrm{H}_{2} \mathrm{O}_{2}$ mediates flow-induced dilation [121]. It was demonstrated that shear stress-induced $\mathrm{H}_{2} \mathrm{O}_{2}$ formation and vasodilation are mediated by $\mathrm{O}_{2}{ }^{-}$originating from mitochondria.

\section{CONCLUDING REMARKS}

It has long been recognized that hemodynamic blood flow induces multiple changes in vascular wall. Much effort has been made to identify "the primary sensor(s)" that serves to detect the shear stress generated by blood flow. Rapid recent development has resulted in the identification of multiple molecules that are involved in early stage of flowsensing in endothelial cells. These include ion channels, cytoskeleton, tyrosine kinase receptors, caveolae, $\mathrm{G}$ proteins, and cell-matrix and cell-cell junction molecules such as integrins, platelet endothelial cell adhesion molecule-1 (PECAM-1) and adherens junction (Fig. 1). Unfortunately, up to the present the "real primary flow sensor" remains elusive.
To qualify as this "real primary flow sensor", such component(s)/molecule(s) should have direct contact with flow and respond very rapidly to flow. Future identification of "primary flow sensor" will probably be dependent on the advancement of new biophysical technologies which can detect rapid change in protein conformation/structures. Targeted knockdown of potential sensor proteins using molecular biological technology may also help to resolve the issue. Taken together, on the voyage to search for the "primary flow sensor" of vascular endothelial cells, there is spacious avenue ahead of us.

\section{REFERENCES}

[1] Badimon, L.; Badimon, J.; Penny, W.; Webster, M.; Chesebro, J.; Fuster, V. Endothelium and atherosclerosis. J. Hypertens. Suppl., 1992, 10, S $43-50$.

[2] Blann, A.; Lip, G. The endothelium in atherothrombotic disease: assessment of function, mechanisms and clinical implications. Blood Coagul. Fibrinolysis., 1998, 9, 297-306.

[3] Quyyumi, A. Endothelial function in health and disease: new insights into the genesis of cardiovascular disease. Am. J. Med., 1998, 105, 32S-39S.

[4] Davies, P.; Barbee, K.; Volin, M.; Robotewskyj, A.; Chen, J.; 
Joseph, L.; Griem, M.; Wernick, M.; Jacobs, E.; Polacek, D.; dePaola, N.; Barakat, A. Spatial relationships in early signaling events of flow-mediated endothelial mechanotransduction. Аппи. Rev. Physiol., 1997, 59, 527-549.

[5] Davies, P. Flow-mediated endothelial mechanotransduction. Physiol. Rev., 1995, 75, 519-560.

[6] Folgering, J.; Sharif-Naeini, R.; Dedman, A.; Patel, A.; Delmas, P.; Honoré, E. Molecular basis of the mammalian pressure-sensitive ion channels: focus on vascular mechanotransduction. Prog. Biophys. Mol. Biol., 97, 180-195.

[7] Li, Y.; Haga, J.; Chien, S. Molecular basis of the effects of shear stress on vascular endothelial cells. J. Biomech., 2005, 38, 19491971.

[8] Cosens, D.; Manning, A. Abnormal electroretinogram from a Drosophila mutant. Nature, 1969, 224, 285-287.

[9] Christensen, A.; Corey, D. TRP channels in mechanosensation: direct or indirect activation? Nat. Rev. Neurosci., 2007, 8, 510-521.

[10] Nauli, S.; Kawanabe, Y.; Kaminski, J.; Pearce, W.; Ingber, D.; Zhou, J. Endothelial cilia are fluid shear sensors that regulate calcium signaling and nitric oxide production through polycystin-1. Circulation, 2008, 117, 1161-1171.

[11] Köhler, R.; Heyken, W.; Heinau, P.; Schubert, R.; Si, H.; Kacik, M.; Busch, C.; Grgic, I.; Maier, T.; Hoyer, J. Evidence for a functional role of endothelial transient receptor potential V4 in shear stress-induced vasodilatation. Arterioscler. Thromb. Vasc. Biol., 2006, 26, 1495-1502.

[12] Liu, C.; Huang, Y.; Ngai, C.; Leung, Y.; Yao, X. TRPC3 is involved in flow- and bradykinin-induced vasodilation in rat small mesenteric arteries. Acta. Pharmacol. Sin., 2006, 27, 981-990.

[13] Oancea, E.; Wolfe, J.; Clapham, D. Functional TRPM7 channels accumulate at the plasma membrane in response to fluid flow. Circ. Res., 2006, 98, 245-253.

[14] Delmas, P. Polycystins: polymodal receptor/ion-channel cellular sensors. Pflugers. Arch., 2005, 451, 264-276.

[15] Bichet, D.; Peters, D.; Patel, A.; Delmas, P.; Honoré, E. Cardiovascular polycystins: insights from autosomal dominant polycystic kidney disease and transgenic animal models. Trends Cardiovasc. Med., 2006, 16, 292-298.

[16] Mochizuki, T.; Wu, G.; Hayashi, T.; Xenophontos, S.; Veldhuisen, B.; Saris, J.; Reynolds, D.; Cai, Y.; Gabow, P.; Pierides, A.; Kimberling, W.; Breuning, M.; Deltas, C.; Peters, D.; Somlo, S. PKD2, a gene for polycystic kidney disease that encodes an integral membrane protein. Science, 1996, 272, 1339-1342.

[17] Hanaoka, K.; Qian, F.; Boletta, A.; Bhunia, A.; Piontek, K.; Tsiokas, L.; Sukhatme, V.; Guggino, W.; Germino, G. Coassembly of polycystin-1 and -2 produces unique cation-permeable currents. Nature, 408, 990-994.

[18] Nauli, S.; Alenghat, F.; Luo, Y.; Williams, E.; Vassilev, P.; Li, X.; Elia, A.; Lu, W.; Brown, E.; Quinn, S.; Ingber, D.; Zhou, J. Polycystins 1 and 2 mediate mechanosensation in the primary cilium of kidney cells. Nat. Genet., 2003, 33, 129-137.

[19] AbouAlaiwi, W.A.; Takahashi, M.; Mell, B.R.; Jones, T.J.; Ratnam, S.; Kolb, R. J.; Nauli, S.M. Ciliary polycystin-2 is a mechanosensitive calcium channel involved in nitric oxide signaling cascades. Circ. Res., 2009, 104, 860-869.

[20] Watanabe, H.; Davis, J.; Smart, D.; Jerman, J.; Smith, G.; Hayes, P.; Vriens, J.; Cairns, W.; Wissenbach, U.; Prenen, J.; Flockerzi, V.; Droogmans, G.; Benham, C.; Nilius, B. Activation of TRPV4 channels (hVRL-2/mTRP12) by phorbol derivatives. J. Biol. Chem., 2002, 277, 13569-13577.

[21] Strotmann, R.; Harteneck, C.; Nunnenmacher, K.; Schultz, G.; Plant, T. OTRPC4, a nonselective cation channel that confers sensitivity to extracellular osmolarity. Nat. Cell. Biol., 2000, 2, 695-702.

[22] Gao, X.; Wu, L.; O'Neil, R. Temperature-modulated diversity of TRPV4 channel gating: activation by physical stresses and phorbol ester derivatives through protein kinase C-dependent and independent pathways. J. Biol. Chem., 2003, 278, 27129-27137.

[23] Güler, A.; Lee, H.; Iida, T.; Shimizu, I.; Tominaga, M.; Caterina, M. Heat-evoked activation of the ion channel, TRPV4. J. Neurosci., 2002, 22, 6408-6414.

[24] Suzuki, M.; Mizuno, A.; Kodaira, K.; Imai, M. Impaired pressure sensation in mice lacking TRPV4. J. Biol. Chem., 2003, 278, 22664-22668.

[25] Watanabe, H.; Vriens, J.; Prenen, J.; Droogmans, G.; Voets, T.; Nilius, B. Anandamide and arachidonic acid use epoxyeicosatrienoic acids to activate TRPV4 channels. Nature, 2003, 424, 434-
438.

[26] Wu, L.; Gao, X.; Brown, R. C.; Heller, S.; O'Neil, R. G. Dual role of the TRPV4 channel as a sensor of flow and osmolality in renal epithelial cells. Am. J. Physiol. Renal. Physiol., 2007, 293, F16991713.

[27] Hartmannsgruber, V.; Heyken, W. T.; Kacik, M.; Kaistha, A.; Grgic, I.; Harteneck, C.; Liedtke, W.; Hoyer, J.; Kohler, R. Arterial response to shear stress critically depends on endothelial TRPV4 expression. PLoS One, 2007, 2, e827.

[28] Birnbaumer, L.; Zhu, X.; Jiang, M.; Boulay, G.; Peyton, M.; Vannier, B.; Brown, D.; Platano, D.; Sadeghi, H.; Stefani, E.; Birnbaumer, M. On the molecular basis and regulation of cellular capacitative calcium entry: roles for Trp proteins. Proc. Natl. Acad. Sci. U S A., 1996, 93, 15195-15202.

[29] Montell, C. Physiology, phylogeny, and functions of the TRP superfamily of cation channels. Sci. STKE, 2001, 2001, review 1.

[30] Trebak, M.; Vazquez, G.; Bird, G.; Putney, J. J. The TRPC3/6/7 subfamily of cation channels. Cell. Calcium, 33, 451-461.

[31] He, Y.; Yao, G.; Savoia, C.; Touyz, R. Transient receptor potential melastatin 7 ion channels regulate magnesium homeostasis in vascular smooth muscle cells: role of angiotensin II. Circ. Res., 2005, 96, 207-215.

[32] Runnels, L.; Yue, L.; Clapham, D. TRP-PLIK, a bifunctional protein with kinase and ion channel activities. Science, 2001, 291, 1043-1047.

[33] Numata, T.; Shimizu, T.; Okada, Y. Direct mechano-stress sensitivity of TRPM7 channel. Cell. Physiol. Biochem., 2007, 19, 1-8.

[34] North, R. Molecular physiology of P2X receptors. Physiol. Rev., 2002, 82, 1013-1067.

[35] Vial, C.; Roberts, J.; Evans, R. Molecular properties of ATP-gated P2X receptor ion channels. Trends Pharmacol. Sci., 2004, 25, $487-$ 493.

[36] Glass, R.; Burnstock, G. Immunohistochemical identification of cells expressing ATP-gated cation channels ( $\mathrm{P} 2 \mathrm{X}$ receptors) in the adult rat thyroid. J. Anat., 2001, 198, 569-579.

[37] Ray, F.; Huang, W.; Slater, M.; Barden, J. Purinergic receptor distribution in endothelial cells in blood vessels: a basis for selection of coronary artery grafts. Atherosclerosis, 2002, 162, 55-61.

[38] Yamamoto, K.; Korenaga, R.; Kamiya, A.; Qi, Z.; Sokabe, M. Ando, J. P2X(4) receptors mediate ATP-induced calcium influx in human vascular endothelial cells. Am. J. Physiol. Heart. Circ. Physiol., 2000, 279, H285-292.

[39] Yamamoto, K.; Korenaga, R.; Kamiya, A.; Ando, J. Fluid shear stress activates $\mathrm{Ca}(2+)$ influx into human endothelial cells via P2X4 purinoceptors. Circ. Res., 2000, 87, 385-391.

[40] Yamamoto, K.; Sokabe, T.; Matsumoto, T.; Yoshimura, K.; Shibata, M.; Ohura, N.; Fukuda, T.; Sato, T.; Sekine, K.; Kato, S.; Isshiki, M.; Fujita, T.; Kobayashi, M.; Kawamura, K.; Masuda, H.; Kamiya, A.; Ando, J. Impaired flow-dependent control of vascular tone and remodeling in P2X4-deficient mice. Nat. Med., 2006, 12 , 133-137.

[41] Olesen, S.; Clapham, D.; Davies, P. Haemodynamic shear stress activates a $\mathrm{K}+$ current in vascular endothelial cells. Nature, 1988, 331, 168-170.

[42] Nakache, M.; Gaub, H. Hydrodynamic hyperpolarization of endothelial cells. Proc. Natl. Acad. Sci. USA, 1988, 85, 1841-1843.

[43] Uematsu, M.; Ohara, Y.; Navas, J.; Nishida, K.; Murphy, T.; Alexander, R.; Nerem, R.; Harrison, D. Regulation of endothelial cell nitric oxide synthase mRNA expression by shear stress. Am. J. Physiol., 1995, 269, C1371-1378.

[44] Ohno, M.; Cooke, J.; Dzau, V.; Gibbons, G. Fluid shear stress induces endothelial transforming growth factor beta-1 transcription and production. Modulation by potassium channel blockade. $J$. Clin. Invest., 1995, 95, 1363-1369.

[45] Hoger, J.; Ilyin, V.; Forsyth, S.; Hoger, A. Shear stress regulates the endothelial Kir2.1 ion channel. Proc. Natl. Acad. Sci. USA, 2002, 99, 7780-7785.

[46] Sun, D.; Huang, A.; Koller, A.; Kaley, G. Endothelial K(ca) channels mediate flow-dependent dilation of arterioles of skeletal muscle and mesentery. Microvasc. Res., 2001, 61, 179-186.

[47] Barakat, A.; Leaver, E.; Pappone, P.; Davies, P. A flow-activated chloride-selective membrane current in vascular endothelial cells. Circ. Res., 1999, 85, 820-828.

[48] Lieu, D.; Pappone, P.; Barakat, A. Differential membrane potential and ion current responses to different types of shear stress in vascular endothelial cells. Am. J. Physiol. Cell. Physiol., 2004, 286, 
C1367-1375.

[49] Barakat, A.; Lieu, D.; Gojova, A. Secrets of the code: do vascular endothelial cells use ion channels to decipher complex flow signals? Biomaterials, 2006, 27, 671-678.

[50] Jow, F.; Numann, R. Fluid flow modulates calcium entry and activates membrane currents in cultured human aortic endothelial cells. J. Membr. Biol., 1999, 171, 127-139.

[51] Romanenko, V.; Davies, P.; Levitan, I. Dual effect of fluid shear stress on volume-regulated anion current in bovine aortic endothelial cells. Am. J. Physiol. Cell. Physiol., 2002, 282, C708-718.

[52] Wang, Y.; Miao, H.; Li, S.; Chen, K.; Li, Y.; Yuan, S.; Shyy, J.; Chien, S. Interplay between integrins and FLK-1 in shear stressinduced signaling. Am. J. Physiol. Cell. Physiol., 2002, 283, C1540-1547.

[53] Chen, K.; Li, Y.; Kim, M.; Li, S.; Yuan, S.; Chien, S.; Shyy, J. Mechanotransduction in response to shear stress. Roles of receptor tyrosine kinases, integrins, and Shc. J. Biol. Chem., 1999, 274, 18393-18400.

[54] Tzima, E.; del Pozo, M.; Shattil, S.; Chien, S.; Schwartz, M. Activation of integrins in endothelial cells by fluid shear stress mediates Rho-dependent cytoskeletal alignment. EMBO J, 2001, 20, 46394647.

[55] Jalali, S.; del Pozo , M.; Chen, K.; Miao, H.; Li, Y.; Schwartz, M.; Shyy, J.; Chien, S. Integrin-mediated mechanotransduction requires its dynamic interaction with specific extracellular matrix (ECM) ligands. Proc. Natl. Acad. Sci. USA, 2001, 98, 1042-1046.

[56] Muller, J.; Chilian, W.; Davis, M. Integrin signaling transduces shear stress--dependent vasodilation of coronary arterioles. Circ. Res., 1997, 80, 320-326.

[57] DeLisser, H.; Christofidou-Solomidou, M.; Strieter, R.; Burdick, M.; Robinson, C.; Wexler, R.; Kerr, J.; Garlanda, C.; Merwin, J.; Madri, J.; Albelda, S. Involvement of endothelial PECAM-1/CD31 in angiogenesis. Am. J. Pathol., 1997, 151, 671-677.

[58] Osawa, M.; Masuda, M.; Harada, N.; Lopes, R.; Fujiwara, K. Tyrosine phosphorylation of platelet endothelial cell adhesion molecule1 (PECAM-1, CD31) in mechanically stimulated vascular endothelial cells. Eur. J. Cell. Biol., 1997, 72, 229-237.

[59] Harada, N.; Masuda, M.; Fujiwara, K. Fluid flow and osmotic stress induce tyrosine phosphorylation of an endothelial cell 128 kDa surface glycoprotein. Biochem. Biophys. Res. Commun., 1995, 214, 69-74.

[60] Osawa, M.; Masuda, M.; Kusano, K.; Fujiwara, K. Evidence for a role of platelet endothelial cell adhesion molecule-1 in endothelial cell mechanosignal transduction: is it a mechanoresponsive molecule? J. Cell. Biol., 2002, 158, 773-785.

[61] Dejana, E.; Bazzoni, G.; Lampugnani, M. Vascular endothelial (VE)-cadherin: only an intercellular glue? Exp. Cell. Res., 1999, 252, 13-19.

[62] Carmeliet, P.; Lampugnani, M.; Moons, L.; Breviario, F.; Compernolle, V.; Bono, F.; Balconi, G.; Spagnuolo, R.; Oosthuyse, B.; Dewerchin, M.; Zanetti, A.; Angellilo, A.; Mattot, V.; Nuyens, D.; Lutgens, E.; Clotman, F.; de Ruiter, M.; Gittenberger-de Groot, A.; Poelmann, R.; Lupu, F.; Herbert, J.; Collen, D.; Dejana, E. Targeted deficiency or cytosolic truncation of the VE-cadherin gene in mice impairs VEGF-mediated endothelial survival and angiogenesis. Cell, 1999, 98, 147-157.

[63] Schnittler, H.; Püschel, B.; Drenckhahn, D. Role of cadherins and plakoglobin in interendothelial adhesion under resting conditions and shear stress. Am. J. Physiol., 1997, 273, H2396-2405.

[64] Noria, S.; Cowan, D.; Gotlieb, A.; Langille, B. Transient and steady-state effects of shear stress on endothelial cell adherens junctions. Circ. Res., 1999, 85, 504-514.

[65] Shay-Salit, A.; Shushy, M.; Wolfovitz, E.; Yahav, H.; Breviario, F.; Dejana, E.; Resnick, N. VEGF receptor 2 and the adherens junction as a mechanical transducer in vascular endothelial cells. Proc. Natl. Acad. Sci. USA, 2002, 99, 9462-9467.

[66] Jin, Z.; Ueba, H.; Tanimoto, T.; Lungu, A.; Frame, M.; Berk, B. Ligand-independent activation of vascular endothelial growth factor receptor 2 by fluid shear stress regulates activation of endothelial nitric oxide synthase. Circ. Res., 2003, 93, 354-363.

[67] Rizzo, V.; McIntosh, D.; Oh, P.; Schnitzer, J. In situ flow activates endothelial nitric oxide synthase in luminal caveolae of endothelium with rapid caveolin dissociation and calmodulin association. $J$. Biol. Chem., 1998, 273, 34724-34729.

[68] Rizzo, V.; Sung, A.; Oh, P.; Schnitzer, J. Rapid mechanotransduction in situ at the luminal cell surface of vascular endothelium and its caveolae. J. Biol. Chem., 1998, 273, 26323-26329.

[69] Schnitzer, J.; Oh, P.; Jacobson, B.; Dvorak, A. Caveolae from luminal plasmalemma of rat lung endothelium: microdomains enriched in caveolin, $\mathrm{Ca}(2+)$-ATPase, and inositol trisphosphate receptor. Proc. Natl. Acad. Sci. USA, 1995, 92, 1759-1763.

[70] Sun, R.; Muller, S.; Stoltz, J.; Wang, X. Shear stress induces caveolin-1 translocation in cultured endothelial cells. Eur. Biophys. J., 2002, 30, 605-611.

[71] Boyd, N.; Park, H.; Yi, H.; Boo, Y.; Sorescu, G.; Sykes, M.; Jo, H. Chronic shear induces caveolae formation and alters ERK and Akt responses in endothelial cells. Am. J. Physiol. Heart Circ. Physiol., 2003, 285, H1113-1122.

[72] Rizzo, V.; Morton, C.; DePaola, N.; Schnitzer, J.; Davies, P. Recruitment of endothelial caveolae into mechanotransduction pathways by flow conditioning in vitro. Am. J. Physiol. Heart Circ. Physiol., 2003, 285, H1720-1729.

[73] Sun, R.; Muller, S.; Zhuang, F.; Stoltz, J.; Wang, X. Caveolin-1 redistribution in human endothelial cells induced by laminar flow and cytokine. Biorheology, 2003, 40, 31-39.

[74] Park, H.; Go, Y.; St John, P.; Maland, M.; Lisanti, M.; Abrahamson, D.; Jo, H. Plasma membrane cholesterol is a key molecule in shear stress-dependent activation of extracellular signal-regulated kinase. J. Biol. Chem., 1998, 273, 32304-32311.

[75] Lungu, A.; Jin, Z.; Yamawaki, H.; Tanimoto, T.; Wong, C.; Berk, B. Cyclosporin A inhibits flow-mediated activation of endothelial nitric-oxide synthase by altering cholesterol content in caveolae. $J$. Biol. Chem., 2004, 279, 48794-48800.

[76] Yu, J.; Bergaya, S.; Murata, T.; Alp, I.; Bauer, M.; Lin, M.; Drab, M.; Kurzchalia, T.; Stan, R.; Sessa, W. Direct evidence for the role of caveolin-1 and caveolae in mechanotransduction and remodeling of blood vessels. J. Clin. Invest., 2006, 116, 1284-1291.

[77] Gudi, S.; Clark, C.; Frangos, J. Fluid flow rapidly activates G proteins in human endothelial cells. Involvement of $\mathrm{G}$ proteins in mechanochemical signal transduction. Circ. Res., 1996, 79, 834839.

[78] Gudi, S.; Huvar, I.; White, C.; McKnight, N.; Dusserre, N.; Boss, G.; Frangos, J. Rapid activation of Ras by fluid flow is mediated by Galpha(q) and Gbetagamma subunits of heterotrimeric G proteins in human endothelial cells. Arterioscler. Thromb. Vasc. Biol., 2003, 23, 994-1000.

[79] Jo, H.; Sipos, K.; Go, Y.; Law, R.; Rong, J.; McDonald, J. Differential effect of shear stress on extracellular signal-regulated kinase and N-terminal Jun kinase in endothelial cells. Gi2- and Gbeta/gamma-dependent signaling pathways. J. Biol. Chem., 1997, 272, 1395-1401

[80] Gudi, S.; Nolan, J.; Frangos, J. Modulation of GTPase activity of G proteins by fluid shear stress and phospholipid composition. Proc. Natl. Acad. Sci. USA, 1998, 95, 2515-2519.

[81] Vink, H.; Duling, B. Identification of distinct luminal domains for macromolecules, erythrocytes, and leukocytes within mammalian capillaries. Circ. Res., 1996, 79, 581-589.

[82] Weinbaum, S.; Tarbell, J.; Damiano, E. The structure and function of the endothelial glycocalyx layer. Ann. Rev. Biomed. Eng., 2007, 9, 121-167.

[83] Florian, J.; Kosky, J.; Ainslie, K.; Pang, Z.; Dull, R.; Tarbell, J. Heparan sulfate proteoglycan is a mechanosensor on endothelial cells. Circ. Res., 2003, 93, e136-142.

[84] Yao, Y.; Rabodzey, A.; Dewey, C. J. Glycocalyx modulates the motility and proliferative response of vascular endothelium to fluid shear stress. Am. J. Physiol. Heart Circ. Physiol., 2007, 293, H1023-1030.

[85] Mochizuki, S.; Vink, H.; Hiramatsu, O.; Kajita, T.; Shigeto, F.; Spaan, J.; Kajiya, F. Role of hyaluronic acid glycosaminoglycans in shear-induced endothelium-derived nitric oxide release. Am. J. Physiol. Heart Circ. Physiol., 2003, 285, H722-726.

[86] Ainslie, K.; Garanich, J.; Dull, R.; Tarbell, J. Vascular smooth muscle cell glycocalyx influences shear stress-mediated contractile response. J. Appl. Physiol., 2005, 98, 242-249.

[87] Nieuwdorp, M.; Meuwese, M.; Vink, H.; Hoekstra, J.; Kastelein, J.; Stroes, E. The endothelial glycocalyx: a potential barrier between health and vascular disease. Curr. Opin. Lipidol., 2005, 16, 507511.

[88] Ali, M.; Schumacker, P. Endothelial responses to mechanical stress: where is the mechanosensor? Crit. Care Med., 2002, 30, S198-206.

[89] Barbee, K.; Mundel, T.; Lal, R.; Davies, P. Subcellular distribution 
of shear stress at the surface of flow-aligned and nonaligned endothelial monolayers. Am. J. Physiol., 1995, 268, H1765-1772.

[90] Barbee, K.; Davies, P.; Lal, R. Shear stress-induced reorganization of the surface topography of living endothelial cells imaged by atomic force microscopy. Circ. Res., 1994, 74, 163-171.

[91] Helmke, B.; Davies, P. The cytoskeleton under external fluid mechanical forces: hemodynamic forces acting on the endothelium. Ann. Biomed. Eng., 2002, 30, 284-296.

[92] Ingber, D. Tensegrity: the architectural basis of cellular mechanotransduction. Ann. Rev. Physiol., 1997, 59, 575-599.

[93] Bojanowski, K.; Maniotis, A.; Plisov, S.; Larsen, A.; Ingber, D. DNA topoisomerase II can drive changes in higher order chromosome architecture without enzymatically modifying DNA. J. Cell. Biochem., 1998, 69, 127-142.

[94] Ingber, D. In search of cellular control: signal transduction in context. J. Cell. Biochem. Suppl., 1998, 30-31, 232-237.

[95] Pourati, J.; Maniotis, A.; Spiegel, D.; Schaffer, J.; Butler, J.; Fredberg, J.; Ingber, D.; Stamenovic, D.; Wang, N. Is cytoskeletal tension a major determinant of cell deformability in adherent endothelial cells? Am. J. Physiol., 1998, 274, C1283-1289.

[96] Maniotis, A.; Bojanowski, K.; Ingber, D. Mechanical continuity and reversible chromosome disassembly within intact genomes removed from living cells. J. Cell. Biochem., 1997, 65, 114-130.

[97] Knudsen, H.; Frangos, J. Role of cytoskeleton in shear stressinduced endothelial nitric oxide production. Am. J. Physiol., 1997, 273, H347-355.

[98] Imberti, B.; Morigi, M.; Zoja, C.; Angioletti, S.; Abbate, M.; Remuzzi, A.; Remuzzi, G. Shear stress-induced cytoskeleton rearrangement mediates NF-kappaB-dependent endothelial expression of ICAM-1. Microvasc. Res., 2000, 60, 182-188.

[99] Helmke, B.; Goldman, R.; Davies, P. Rapid displacement of vimentin intermediate filaments in living endothelial cells exposed to flow. Circ. Res., 2000, 86, 745-752.

[100] Henrion, D.; Terzi, F.; Matrougui, K.; Duriez, M.; Boulanger, C.; Colucci-Guyon, E.; Babinet, C.; Briand, P.; Friedlander, G.; Poitevin, P.; Lévy, B. Impaired flow-induced dilation in mesenteric resistance arteries from mice lacking vimentin. J. Clin. Invest., 1997, 100, 2909-2914.

[101] Tsuruta, D.; Jones, J. The vimentin cytoskeleton regulates focal contact size and adhesion of endothelial cells subjected to shear stress. J. Cell. Sci., 2003, 116, 4977-4984.

[102] Busse, R.; Edwards, G.; Félétou, M.; Fleming, I.; Vanhoutte, P.; Weston, A. EDHF: bringing the concepts together. Trends Pharmacol. Sci., 2002, 23, 374-380.

[103] Shimokawa, H.; Yasutake, H.; Fujii, K.; Owada, M.; Nakaike, R.; Fukumoto, Y.; Takayanagi, T.; Nagao, T.; Egashira, K.; Fujishima, M.; Takeshita, A. The importance of the hyperpolarizing mechanism increases as the vessel size decreases in endotheliumdependent relaxations in rat mesenteric circulation. J. Cardiovasc. Pharmacol., 1996, 28, 703-711.

[104] Cooke, J.; Rossitch, E. J.; Andon, N.; Loscalzo, J.; Dzau, V. Flow activates an endothelial potassium channel to release an endogenous nitrovasodilator. J. Clin. Invest., 1991, 88, 1663-1671.

[105] Hutcheson, I.; Griffith, T. Heterogeneous populations of K+ channels mediate EDRF release to flow but not agonists in rabbit aorta. Am. J. Physiol., 1994, 266, H590-596.

[106] Loot, A.; Popp, R.; Fisslthaler, B.; Vriens, J.; Nilius, B.; Fleming, I. Role of cytochrome P450-dependent transient receptor potential V4 activation in flow-induced vasodilatation. Cardiovasc. Res., 2008, $80,445-452$

[107] Miura, H.; Bosnjak, J.; Ning, G.; Saito, T.; Miura, M.; Gutterman, D. Role for hydrogen peroxide in flow-induced dilation of human coronary arterioles. Circ. Res., 2003, 92, e31-40.

[108] Liu, C.; Ngai, C. Y.; Huang, Y.; Ko, W. H.; Wu, M.; He, G. W.; Garland, C. J.; Dora, K. A.; Yao, X. Depletion of intracellular $\mathrm{Ca} 2+$ stores enhances flow-induced vascular dilatation in rat small mesenteric artery. Br. J. Pharmacol., 2006, 147, 506-515.

[109] Ngai, C. Y.; Huang, Y.; Falck, J. R.; Tang, N. L.; Yao, X. Flow Dilation in Rat Small Mesenteric Arteries Is Mediated by Hydrogen Peroxide Generated from CYP Epoxygenases and Xanthine Oxidase. Open Circul. Vasc. J., 2009, 2, 15-22.

[110] Felty, Q.; Xiong, W.; Sun, D.; Sarkar, S.; Singh, K.; Parkash, J.; Roy, D. Estrogen-induced mitochondrial reactive oxygen species as signal-transducing messengers. Biochemistry, 2005, 44, 6900-6909.

[111] Kimura, S.; Zhang, G.; Nishiyama, A.; Shokoji, T.; Yao, L.; Fan, Y.; Rahman, M.; Suzuki, T.; Maeta, H.; Abe, Y. Role of NAD(P)H oxidase- and mitochondria-derived reactive oxygen species in cardioprotection of ischemic reperfusion injury by angiotensin II. $\mathrm{Hy}$ pertension, 2005, 45, 860-866.

[112] Waypa, G.; Marks, J.; Mack, M.; Boriboun, C.; Mungai, P.; Schumacker, P. Mitochondrial reactive oxygen species trigger calcium increases during hypoxia in pulmonary arterial myocytes. Circ. Res., 2002, 91, 719-726.

[113] Cai, H.; Li, Z.; Dikalov, S.; Holland, S.; Hwang, J.; Jo, H.; Dudley, S. J.; Harrison, D. NAD $(\mathrm{P}) \mathrm{H}$ oxidase-derived hydrogen peroxide mediates endothelial nitric oxide production in response to angiotensin II. J. Biol. Chem., 2002, 277, 48311-48317.

[114] Li, J.; Shah, A. Endothelial cell superoxide generation: regulation and relevance for cardiovascular pathophysiology. Am. J. Physiol. Regul. Integr. Comp. Physiol., 2004, 287, R1014-1030.

[115] Yan, C.; Huang, A.; Wu, Z.; Kaminski, P.; Wolin, M.; Hintze, T.; Kaley, G.; Sun, D. Increased superoxide leads to decreased flowinduced dilation in resistance arteries of Mn-SOD-deficient mice. Am. J. Physiol. Heart Circ. Physiol., 2005, 288, H2225-2231.

[116] Han, D.; Antunes, F.; Canali, R.; Rettori, D.; Cadenas, E. Voltagedependent anion channels control the release of the superoxide anion from mitochondria to cytosol. J. Biol. Chem., 2003, 278, 55575563.

[117] Phillips, S.; Hatoum, O.; Gutterman, D. The mechanism of flowinduced dilation in human adipose arterioles involves hydrogen peroxide during CAD. Am. J. Physiol. Heart Circ. Physiol., 2007, 292, H93-100.

[118] Mueller, C.; Laude, K.; McNally, J.; Harrison, D. ATVB in focus: redox mechanisms in blood vessels. Arterioscler. Thromb. Vasc. Biol., 2005, 25, 274-278.

[119] Wagner, A.; Schroeter, M.; Hecker, M. 17beta-estradiol inhibition of NADPH oxidase expression in human endothelial cells. FASEB J., 2001, 15, 2121-2130.

[120] Silacci, P.; Desgeorges, A.; Mazzolai, L.; Chambaz, C.; Hayoz, D. Flow pulsatility is a critical determinant of oxidative stress in endothelial cells. Hypertension, 2001, 38, 1162-1166.

[121] Liu, Y.; Zhao, H.; Li, H.; Kalyanaraman, B.; Nicolosi, A.; Gutterman, D. Mitochondrial sources of $\mathrm{H}_{2} \mathrm{O}_{2}$ generation play a key role in flow-mediated dilation in human coronary resistance arteries. Circ. Res., 2003, 93, 573-580. 